\title{
A Cross-Lagged Path Analysis of Five Intrapersonal Determinants of Smoking Cessation
}

\author{
Yessenia Castro ${ }^{\mathrm{a}}$, Miguel Ángel Cano ${ }^{\mathrm{b}}$, Michael S. Businelle ${ }^{\mathrm{c}}$, Virmarie Correa-Fernández $^{\mathrm{b}}$, \\ Whitney L. Heppnerd, Carlos A. Mazas ${ }^{b}$, and David W. Wetter ${ }^{b}$ \\ aSchool of Social Work, The University of Texas at Austin; 1 University Station, D3500, Austin, \\ Texas, 78712 \\ bDepartment of Health Disparities Research, The University of Texas MD Anderson Cancer \\ Center; Unit 1440, PO Box 301402, Houston, Texas, 77230 \\ 'Division of Health Promotion and Behavioral Science, The University of Texas School of Public \\ Health Dallas Regional Campus, 5323 Harry Hines Blvd., V8.112 Dallas, TX 75390-9128 \\ dDepartment of Psychological Science, Georgia College and State University, 1-03 Arts \& \\ Sciences Bldg, Milledgeville, Georgia, 31061
}

\section{Abstract}

Background-Prominent theories of drug use underscore the importance of considering the inter-relationships (e.g., reciprocal relations, indirect effects) of determinants of drug use behavior. In the area of smoking, few studies have examined multiple determinants of cessation in this way, and in prospective analyses. The current study is an examination of the prospective cross-lagged relationships among five intrapersonal determinants of cessation:

Methods-Data from a longitudinal cohort study on racial differences in the process of smoking cessation were used to examine reciprocal relations among abstinence motivation, abstinence selfefficacy, positive affect, negative affect, and craving. Each of these five measures assessed on the quit day were regressed onto the same measures assessed 1-2 weeks pre-quit. The relationships of these variables at quit day with 1-week post-quit abstinence from smoking were also examined.

Results-When the five variables were examined simultaneously in a cross-lagged path analysis, motivation and self-efficacy, and self-efficacy and positive affect showed cross-lagged relations.

() 2014 Elsevier Ireland Ltd. All rights reserved.

Address Correspondence to: Yessenia Castro; The University of Texas at Austin School of Social Work. 1 University Station, D3500, Austin, TX, 78712. Phone: 512-471-1691, Fax: 512-471-9600; ycastro@ austin.utexas.edu.

Publisher's Disclaimer: This is a PDF file of an unedited manuscript that has been accepted for publication. As a service to our customers we are providing this early version of the manuscript. The manuscript will undergo copyediting, typesetting, and review of the resulting proof before it is published in its final citable form. Please note that during the production process errors may be discovered which could affect the content, and all legal disclaimers that apply to the journal pertain.

Disclosures

Contributors: YC and DWW conceived of the study and drafted the manuscript; MAC assisted with drafting the manuscript; MSB assisted with analyses; MAC, VCF, WLH, CAM, and MSB consulted on the study design and on drafts of the manuscript. All authors approved the final manuscript.

Conflict of Interest: The authors have no conflicts of interest pertaining to this work. 
Only self-efficacy on the quit day uniquely predicted 1-week post quit abstinence. There were significant indirect effects of motivation and positive affect on cessation via self-efficacy.

Conclusions-The current study reaffirms the importance of motivation and self-efficacy in smoking cessation, and suggests that positive affect may play a role in smoking cessation.

\section{Keywords}

smoking cessation; motivation; affect; craving; self-efficacy

\section{INTRODUCTION}

Intrapersonal variables have long been regarded as critical determinants of drug use and cessation, with certain variables repeatedly emphasized. Prominent models of addiction emphasize the critical role of motivation (DiClemente, 1999; Miller and Rollnick, 2002; Witkiewitz and Marlatt, 2004), self-efficacy (Miller and Rollnick, 2002; Niaura, 2000; Witkiewitz and Marlatt, 2004) and craving (Niaura, 2000; Witkiewitz and Marlatt, 2004). Baker et al. (2004) posit that negative affect is the principal determinant of drug use, while other models (e.g., Niaura, 2000; Witkiewitz and Marlatt, 2004) incorporate both negative and positive affect. These models also propose a complex interplay among these determinants, such as reciprocal relationships and indirect effects. Furthermore, Witkiewitz and Marlatt (2004) emphasized the need for clinical practice to be sensitive to the complex inter-relationships among determinants of drug use and cessation. While the majority of behavioral interventions for drug use target these determinants, this is done with little empirical data on the specific ways in which determinants affect each other to promote or hinder cessation. Treatment research would benefit from a more fine-tuned understanding of the nature of the inter-relationships among the intrapersonal determinants of cessation. Such knowledge may streamline intervention development efforts by highlighting treatment targets that should be addressed in order to maximize the efficacy of treatment.

The current study investigated the prospective cross-lagged relationships among five major intrapersonal determinants of smoking cessation (Niaura, 2000; Witkiewitz and Marlatt, 2004): motivation to abstain from smoking, self-efficacy to abstain from smoking, positive affect, negative affect, and craving. Further, the current study examined the unique prospective associations of these variables with short-term (one-week post-quit) abstinence from smoking. Each of the constructs examined here have been related to smoking cessation in previous studies, but no published research to our knowledge has prospectively examined their reciprocal relationships and their unique effects on cessation in a single model.

\subsection{Motivation}

Motivation represents a level of commitment or desire to reach a stated goal and is a key target of substance use interventions (e.g., motivational interviewing [MI]; Miller and Rollnick, 2002). Motivation predicts smoking cessation (Garvey et al., 1992; Heppner et al., 2011), and is positively related to self-efficacy (Berg et al., 2008; Joseph et al., 2003; Martin et al., 2006). A recent study found that self-efficacy mediated the motivation-cessation 
relationship (Cupertino et al., 2012). Research on the interplay between motivation and other determinants of cessation is lacking.

\subsection{Self-efficacy}

Self-efficacy is defined as one's belief in their ability to perform a specific behavior, and greater self-efficacy should lead to greater likelihood that the behavior is performed (Bandura, 1977). Self-efficacy is a strong predictor of cessation and relapse (Businelle et al., 2011, 2013; Cinciripini et al. 2003; Correa-Fernández et al. 2012; Garvey et al., 1992; Gwaltney et al., 2009). Extant research demonstrates negative associations of self-efficacy with negative affect (Berg et al., 2008; Businelle et al., 2011; Gwaltney et al., 2005; Haukkala et al., 2000; John et al., 2004), and craving/urge (Businelle et al., 2011, 2013; Gwaltney et al., 2005). Limited research suggests a positive association of self-efficacy with positive affect (Martinez et al., 2010).

\subsection{Positive Affect}

Positive affect refers broadly to states of pleasurable engagement and high alertness or energy (Watson et al., 1988). Limited research suggests that positive affect increases the odds of smoking cessation (Doran, et al., 2006). Pharmacological (Doran et al., 2006) and behavioral (Bränström et al., 2010; MachPherson et al., 2010) treatments designed to increase positive affect have been shown to increase cessation rates. al'Absi et al. (2004) found that smokers trying to quit who relapsed reported lower post-quit positive affect compared to those who did not relapse. One study found that inducing positive affect after a self-control-depleting task reduced the odds of smoking after task completion (Shmueli and Prochaska, 2012). Thus, positive affect may promote self-regulation in the process of smoking cessation.

Positive and negative affect are negatively correlated (Watson et al., 1988; Schmukle et al., 2002), and some evidence suggests that positive affect predicts urge to smoke (Zinser et al., 1992). At least one study has demonstrated a negative relationship between positive affect cues and craving (Shiffman et al., 2012).

\subsection{Negative Affect}

Negative affect refers collectively to the full range of negative emotions (e.g., sadness anger, anxiety, guilt, shame; Watson et al., 1988), avoidance of which has long been implicated as a driver of drug use (Witkiwitz and Marlatt, 2004, Baker et al., 2004). Negative affect is associated with a lower probability of smoking cessation (Cofta-Woerpel et al., 2011; Correa-Fernández et al., 2012; Piper et al., 2011) and a majority of lapses occur during negative affect states (Brandon et al., 1994). Also, negative affect is associated with increased craving for cigarettes (Brandon et al., 1996; Businelle et al., 2011; Robinson et al., 2011; Shiyko et al., 2012; Zinser et al., 1992).

\subsection{Craving/Urge}

Craving, a subjective desire to smoke, has been characterized as a strong motivator for smoking (Brandon et al., 1996; Piasecki, 2006). However, research has demonstrated craving to be an inconsistent predictor cessation (Tiffany, 1990; Wray et al., 2013). Post- 
cessation increases in craving are associated with a greater likelihood of smoking relapse (Cofta-Woerpel et al., 2011; Javitz et al., 2012; Killen and Fortmann, 1997), and craving measured post-cessation versus pre-cessation is more strongly associated with relapse (Wray et al., 2013). Craving has been widely studied with negative affect (as noted above), but little is known about how craving relates to other determinants of cessation.

\subsection{Study Purpose}

The current study is a prospective examination of the reciprocal relationships among key determinants of smoking and cessation as hypothesized by prominent models of addiction (Niaura, 2000; Witkiewitz and Marlatt, 2004). Five intrapersonal determinants of cessation (motivation, self-efficacy, positive affect, negative affect, craving) were examined using a prospective, cross-lagged panel design. It was hypothesized that each of the five determinants would predict cessation at one week post quit. Consistent with available research, positive relationships were expected among motivation, self-efficacy and positive affect, as well as between negative affect and craving. Negative affect and craving were expected to be negatively related to motivation, self-efficacy, and positive affect. A fully cross-lagged model incorporating the five determinants was examined for empirical fit and then trimmed to develop the best fitting, most parsimonious model.

\section{METHODS}

\subsection{Participants}

Participants included all 424 individuals who were enrolled in a longitudinal cohort study designed to examine the social determinants of smoking cessation. Participants were required to be at least 21 years of age, have smoked at least five cigarettes per day for the past year, have a home address and functioning telephone number, demonstrate proficiency in English at the sixth grade level or higher, and be planning to quit smoking in the next 30 days. Potential participants were excluded if the nicotine patch was contraindicated, if they reported use of tobacco products other than cigarettes, or if they reported participation in a smoking cessation program within the past 90 days.

\subsection{Procedures}

Participants were recruited via local print and radio advertisements to take part in a smoking cessation study. They were first screened via telephone and later in-person to determine eligibility. Verbal informed consent was obtained for the telephone screening, and written informed consent was obtained at the in-person screening/orientation. Because the study was designed to examine determinants of cessation, all enrolled participants were engaged in an active quit attempt, and all received the same treatment. Participants set a quit date approximately 2 weeks after the in-person screening/orientation, received six weeks of nicotine replacement therapy (NRT), six brief smoking cessation counseling sessions based on the Treating Tobacco Use and Dependence Clinical Practice Guideline (Fiore et al., 2000), and self-help materials. These were delivered on a weekly basis beginning one week prior to the quit date and ending four weeks post-quit. Data for the current study were collected at baseline, quit day, and one week post-quit. Each of the five determinants was measured at baseline and on the quit day. Abstinence status was measured at one week post- 
quit. All study procedures were approved by the institutional review board at The University of Texas MD Anderson Cancer Center.

\subsection{Instruments}

2.3.1 Abstinence-Smoking abstinence was a dichotomous variable measured by selfreport of not smoking "even one puff" since the quit day. Self-report of abstinence was confirmed via an expired carbon monoxide measure of less than 10 parts per million. A smoking status of "not abstinent" was imputed for individuals with missing abstinence data at 1 week post-quit.

2.3.2 Craving-Craving was measured using the 4-item Craving subscale of the Wisconsin Smoking Withdrawal Scale (WSWS; Welsch et al., 1999). Participants were asked to rate each symptom on a scale from 0 ("strongly disagree") to 5 ("strongly agree"). Internal consistency reliability for the Craving subscale was .74 at baseline and .85 at quit day.

2.3.3 Motivation-Motivation to abstain from smoking was measured with five items assessing global motivation to abstain from smoking. Participants were asked to indicate level of agreement on a scale of 1 ("strongly disagree") to 5 ("strongly agree") with each item and an average motivation score was computed. Internal consistency reliability for the whole sample was .90 at baseline and .94 on the quit-day. A longer version of this scale has been predictive of smoking relapse (Heppner et al., 2011).

2.3.4 Positive Affect and Negative Affect-Affect was measured at baseline and quit day using the Positive And Negative Affect Schedule (PANAS; Watson et al., 1988). The PANAS is a 20-item measure with two subscales representing two related but distinct affective dimensions. The Positive Affect subscale measures the extent to which a person feels enthusiastic, active, and alert, whereas the Negative Affect subscale measures the extent to which a person feels distress, unpleasantness, or any aversive mood. Participants rate 20 words describing feelings and emotions during the past week on a scale of 1 ("very slightly or not at all") to five ("extremely"). Internal consistency reliability was .94 at both baseline and quit day for Positive Affect. Internal consistency for Negative Affect was .92 at baseline and .91 at quit day.

2.3.5 Self-efficacy-Self-efficacy for smoking abstinence was measured using the SelfEfficacy/Confidence Scale (SECS; Velicer et al., 1990). This is a 9-item scale that measures confidence in one's ability to refrain from smoking in situations characterized by negative affect, positive affect, or habit/craving. Response options range from 1-5 with higher scores indicating greater confidence. The mean score of the 9 items was used in this study. Internal consistency reliability was .85 at baseline and .89 on the quit day.

\subsection{Data Analysis}

Items were examined for significant non-normality as indicated by skewness and kurtosis statistics $>2.0$ and $>4.0$, respectively (Kim, 2012). Path analyses were conducted using maximum likelihood estimation with robust standard errors (MLR) with Monte Carlo 
integration in the Mplus software program. MLR is appropriate for categorical variables and is robust to non-normality in continuous variables (Muthén and Muthén, 2009). However, when used with categorical dependent variables, traditional indices of model fit (e.g, chisquare, RMSEA, CFI, TLI, WRMR) are not available. A baseline model was constructed consisting of autoregressive paths from the 1 week pre-quit measures to quit-day measures, direct paths from the quit-day measures to 1 week post-quit abstinence, the cross-sectional associations among the pre-quit variables, and the cross-sectional associations among the error terms of the quit-day variables. This model was compared to one which additionally contained the cross lagged paths from the 1 week pre-quit measures to the quit-day measures using the MODEL TEST function of Mplus. Once the model with superior fit was established, model trimming was conducted with the superior model by repeating the procedure of constraining the weakest path in the model to zero and testing the model against the model without that path constrained to zero using the MODEL TEST function. This process was repeated until all remaining paths were significant.

\section{RESULTS}

\subsection{Participant Characteristics}

Participant demographics and tobacco use characteristics measured at baseline are presented in Table 1. The sample consisted of roughly equal proportions of individuals self-identifying as White, Black, and Latino. There were significant differences among the three major racial/ethnic groups on all demographic variables as indicated by multivariate analyses of variance or Pearsons' chi square tests where appropriate. As such, participant characteristics are presented separately for each racial/ethnic group, as well as for the whole sample. Table 1 also presents descriptive data for each variable in the model to be tested. There were no significant differences across race/ethnicity for these variables measured pre-quit. On the quit-day, Latinos reported significantly lower levels of self-efficacy and positive affect compared to both African Americans and Whites, and African Americans reported significantly lower levels of craving compared to Whites.

\subsection{Preliminary Analyses}

Skewness and kurtosis statistics were within the acceptable range for all but one variable. Quit-day motivation exhibited significant kurtosis. Missing data on the outcome variable (1week post quit abstinence status) was $18 \%$. Missing data on the continuous variables ranged from $1 \%-18 \%$. Mean number of days between the baseline and quit day assessments was 7.96 days ( (standard deviation $=9.25$ days). The overwhelming majority $(97.5 \%)$ of quit-day assessments were completed within two weeks of the baseline assessment.

Table 2 contains the bivariate correlations among the variables examined. In most instances, the bivariate correlations were consistent with hypotheses. All auto-correlations were significant and medium to large in size. Negative affect and craving were positively related to each other and negatively related to motivation, positive affect and self-efficacy. Motivation, positive affect, and self-efficacy were positively related to each other, and these correlations were small to medium in size. These effects were significant in all but two instances (see Table 2). Only one of the five determinants at the baseline visit was 
significantly associated with abstinence (motivation), as were three of the five variables at quit day (self-efficacy, positive affect, and motivation).

\subsection{Path Analysis}

Comparison of the baseline model - consisting of the autoregressive paths, quit day variables predicting abstinence, and all cross-sectional associations — indicated that the cross-lagged model was a better fit for the data (Wald's $\chi^{2}[20]=115.21, p<.0001$ ). Thus, model trimming proceeded with the cross lagged model. Seventeen paths were systematically removed, resulting in the final model depicted in Figure 1, where all paths are significant at $p<.01$. The current analyses were completed with 1-week post-quit abstinence data in which a "not abstinent" status was imputed for those lost to follow up. This approach has been critiqued for its potential to produce biased estimates (Barnes et al., 2010). To increase confidence in the current findings, model trimming was repeated using abstinence data in which those who were lost to follow up were coded as missing. The resulting final model was identical to the one presented here (with imputed abstinence data).

3.3.1 Post-hoc tests of invariance-Two multiple groups analyses were conducted to determine whether the final model was equally applicable to the three major race/ethnicities represented in the sample, as well as applicable to each gender. A model in which all parameters were allowed to be estimated separately for Whites, African Americans, and Latinos, was compared to a model where parameter estimates were constrained to be equal across groups with the MODEL TEST function. Constraining all model paths to be equal across groups did not result in a significant reduction in model fit (Wald's $\chi^{2}[26]=37.08, p$ $=.07$ ), indicating that the model could be equally applied to African American, White, and Latino smokers. This process was repeated comparing men and women, and results also did not indicate a significant reduction in model fit (Wald's $\chi^{2}[13]=17.04, p=.20$ ), indicating that the model could be equally applied to male and female smokers.

3.3.2 Post-hoc tests of indirect effects-The final model (Figure 1) indicated two possible indirect paths from a pre-quit variable to 1 -week post quit abstinence status through a quit day variable. These were: 1 ) motivation $\rightarrow$ self-efficacy $\rightarrow$ abstinence, and; 2) positive affect $\rightarrow$ self-efficacy $\rightarrow$ abstinence. These indirect paths were modeled and tested for significance using the MODEL CONSTRAINT command of Mplus, and both paths were significant: 1) motivation $\rightarrow$ self-efficacy $\rightarrow$ abstinence; $13(\mathrm{SE}=.052) \mathrm{p}=.008 .2)$ positive affect $\rightarrow$ self-efficacy $\rightarrow$ abstinence; .007 (SE.003), p=.025

\section{DISCUSSION}

The current study utilized a cross-lagged panel design to understand the inter-relationships among five intrapersonal determinants of smoking cessation, as well their unique predictive effects on smoking abstinence during a quit attempt. The final model indicated that two pairs of these variables exhibited reciprocal relationships: motivation to abstain from smoking and smoking abstinence self-efficacy; as well as self-efficacy and positive affect. In addition, quit day self-efficacy significantly predicted one-week post-quit abstinence. 
Regarding motivation and self-efficacy, it is reasonable that having confidence in one's ability to complete a task would increase one's impetus for completing the task. In fact, a major strategy of a prominent motivational approach to drug treatment (Miller and Rollnick, 2002 ) is to affect motivation to change by way of increasing self-efficacy (confidence). That motivation would influence self-efficacy is less obvious; however, one potential explanation is that being more motivated to quit at baseline may inspire one to make greater efforts to prepare for the quit date (e.g., seek out support, identify and address barriers, remove smoking cues from the environment) and exhibit greater persistence in the face of difficulty, which boosts confidence in one's ability to quit.

Only quit-day self-efficacy uniquely predicted abstinence in the current study. In addition, the current study replicated a mediation effect of self-efficacy on the motivation-smoking relationship found in a previous study (Cupertino et al., 2012). This occurred in spite of a number of methodological differences between studies, including examining three additional variables in the current study, use of abstinence as the outcome (vs. cigarettes per day in Cupertino et al.), and use of different measures and conceptualizations of motivation and self-efficacy. Taken together, these findings not only build upon research identifying a cross-sectional association between motivation and self-efficacy (Berg et al., 2008; Joseph et al., 2003; Martin et al., 2006), and support the predictions of prominent models of drug use and treatment (Miller and Rollnick, 2002; Niaura, 2000; Witkiewitz and Marlatt, 2004), but advance increasing self-efficacy as a vital component of cessation interventions.

The role of positive affect in smoking cessation is a relatively understudied area, yet positive affect proved to be useful component of the model by virtue of its relationships with selfefficacy. Although these are novel findings, it is reasonable that self-efficacy may lead to increased positive affect. Given that positive affect is comprised of states of pleasurable engagement, high energy, alertness or enthusiasm (Watson et al., 1988), those who believe that they are capable of making this change may experience some cognitive or behavioral activation in order to prepare themselves and their environment for the quit attempt. Additionally, if the change is perceived as a self-improvement (such as quitting smoking for one's health), self-efficacy may lead to positive affective states such as happiness, excitement, or pride. Reciprocally, the behavioral activation present in those with high positive affect may further encourage efforts to prepare for the quit day, thus increasing selfefficacy. This in turn increases the likelihood of cessation, as indicated by the significant indirect effect of positive affect on cessation via self-efficacy.

Thus, the current study suggests positive affect is a promising target of smoking cessation interventions; however, treatment implications are tempered by the small size of the significant indirect effect, and by the novelty of the finding. Future research would benefit from further exploration of the role of positive affect in the process of smoking cessation. Smoking cessation interventions that incorporate strategies for increasing positive affect are scarce, but one study shows highly promising results (MacPherson et al., 2010). Also, the extant literature already contains numerous evidence-based strategies for increasing positive affect that might improve the efficacy of cessation treatments (e.g., Geschwind et al., 2011; Linehan, 1993; Sheldon and Lyumbomirsky, 2006). 
Pre-quit negative affect was negatively associated with positive affect on the quit day, suggesting that the presence of negative affect can suppress the later experience of positive affect. Future research might further benefit from examining specific dimensions of negative and positive affect to further clarify whether specific aspects of emotion drive this relationship. Negative affect and craving displayed no other significant associations in the model. Although these variables are often considered among the most important determinants of use and cessation (e.g., Baker et al., 2004; Piaseki, 2006), the current study suggests the other variables may have a stronger influence on cessation when considered together. However, it is important to reiterate that participants in this study received NRT and cessation counseling, which could have attenuated the effects of negative affect and craving. The current findings do not negate the abundance of prior research that demonstrates the importance of these variables in drug use and relapse. Rather, it encourages efforts to better understand under what circumstances negative affect and craving have the greatest (or least) influence. Additionally, there may be variables not accounted for here which may interact with craving and negative affect to influence cessation (e.g., access to the drug, as offered by Baker et al., 2004).

It is important to reiterate that the current study examines mechanisms of cessation among individuals receiving both behavioral treatment and pharmacotherapy. The current study has other limitations. The final model was reached through sequential elimination of 17 paths, based on their non-significance. This approach can be quite sensitive to small perturbations of the data, and can inflate the statistical significance of the coefficients of the final model. This study examined 1-week-post-quit abstinence status; thus, the current findings are limited to short-term abstinence. However, given research demonstrating that most lapses into smoking occur in the first eight days after a quit attempt (Hughes et al., 2004), the current results are informative for most quit attempts. This study focused on intrapersonal determinants of drug use, and so cannot speak to the interplay among additional categories of influence considered in prominent models of drug use (e.g., interpersonal, environmental, or demographic variables). In addition, the current study was not exhaustive in the selection of intrapersonal variables for examination. Thus, there is a clear need for additional research on the complex interrelationships of other determinants of cessation. The current sample was racially/ethnically diverse, and the final model provided a good fit to the data across race/ ethnicity. However, lack of differences by race or gender in the post-hoc analyses could have been due to low power. That is, because group differences are inferred via a significant Wald chi square test, it is possible that a lack of a significant Wald's chi square test either indicates that the model is appropriate across race and gender, or that the study was not powered to detect the differences. Although the study sample was very diverse, some racial/ ethnic groups were not represented in this study (e.g., American Indian, and Asian smokers). Finally, it must be noted that although the current study utilized a prospective design, it is nevertheless observational and cannot establish causality; only a true experimental design can do this.

In sum, the current study was a prospective examination of the cross-lagged relations among five intrapersonal determinants of smoking cessation, as well as an examination of their unique predictive effects on smoking abstinence during a quit attempt. Self-efficacy was the only unique direct predictor of abstinence. Two significant cross-lagged relationships were 
found, as well as two significant mediational effects on cessation. The current study reaffirms the importance of motivation and self-efficacy in drug use treatment. Positive affect appears to be worthy of additional research for its potential implications in treatment development. Researchers have traditionally not placed a major focus on enhancing positive affect as a means of encouraging abstinence. No major findings emerged regarding negative affect and craving, despite previous work demonstrating their importance in models of cessation. This suggests a need to examine potential moderators of the relationship of these variables with cessation.

\section{Acknowledgments}

Role of Funding Source: This research was supported by grants from the National Institute on Drug Abuse (R01 DA014818), the National Cancer Institute (K01 CA157689, K07 CA121037, U54 CA153505, R25T CA57730-S2, and P30 CA016672), and the American Cancer Society (MRSGT-12-114-01-CPPB). These funding institutions had no further role in study design; in the collection, analysis and interpretation of data; in the writing of the report; or in the decision to submit the paper for publication. The contents of this research are solely the responsibility of the authors and do not necessarily represent the official views of the National Institutes of Health or the American Cancer Society.

\section{REFERENCES}

al'Absi M, Hatsukami D, Davis GL, Wittmers LE. Prospective examination of effects of smoking abstinence on cortisol and withdrawal symptoms as predictors of early smoking relapse. Drug Alcohol Depend. 2004; 73:267-278. [PubMed: 15036549]

Baker TB, Piper ME, McCarthy DE, Majeskie MR, Fiore MC. Addiction motivation reformulated: an affective processing model of negative reinforcement. Psychol. Rev. 2004; 111:33-51. [PubMed: 14756584]

Bandura A. Self-efficacy: toward a unifying theory of behavioral change. Psychol. Rev. 1977; 84:191215. [PubMed: 847061]

Barnes SA, Larsen MD, Schroeder D, Hanson A, Decker PA. Missing data assumptions and methods in a smoking cessation study. Addiction. 2010; 105:431-437. [PubMed: 20402986]

Berg CJ, Cox LS, Mahnken JD, Greiner KA, Ellerbeck EF. Correlates of self-efficacy among rural smokers. J. Health Psychol. 2008; 13:416-421. [PubMed: 18420774]

Brandon TH, Wetter DW, Baker TB. Affect, expectancies, urges, and smoking: do they conform to models of drug motivation and relapse? Exp. Clin. Psychopharmacol. 1996; 4:29-36.

Bränström R, Penilla C, Pérez-Stable EJ, Muñoz RF. Positive affect and mood management in successful smoking cessation. AmJHealth Behav. 2010; 34:553-562.

Businelle MS, Kendzor DE, Reitzel LR, Costello TJ, Cofta-Woerpel L, Li Y, Mazas CA, Vidrine JI, Cinciripini PM, Greisinger, A.J, Wetter DW. Mechanisms linking socioeconomic status to smoking cessation: a structural equation modeling approach. Health Psychol. 2011; 29:262-273. [PubMed: 20496980]

Businelle MS, Kendzor DE, Reitzel LR, Vidrine JI, Castro Y, Mullen PD, Velasquez MM, CoftaWoerpel L, Cinciripini PM, Greisinger AJ, Wetter DW. Pathways linking socioeconomic status and postpartum smoking relapse. Ann. Behav. Med. 2013; 45:180-191. [PubMed: 23086590]

Cinciripini PM, Wetter DW, Fouladi RT, Blalock JA, Carter BL, Cinciripini LG, Bailey WF. The effects of depressed mood on smoking cessation: mediation by post-cessation self-efficacy. J. Consult. Clin. Psychol. 2003; 71:292-301. [PubMed: 12699023]

Cofta-Woerpel L, McClure JB, Urbauer D, Cinciripini PM, Wetter DW. Early cessation success or failure among women attempting to quit smoking: trajectories and volatility of urge and negative mood during the first post-cessation week. J. Abnorm. Psychol. 2011; 120:596-606. [PubMed: 21574667]

Correa-Fernández V, Ji L, Castro Y, Heppner WL, Vidrine JI, Costello TJ, Mullen, P.D, CoftaWoerpel L, Velasquez MM, Greisinger A, Cinciripini PM, Wetter DW. Mediators of the 
association of major depressive syndrome and anxiety syndrome with postpartum smoking relapse. J. Consult. Clin. Psychol. 2012; 80:636-648. [PubMed: 22390410]

Cupertino AP, Berg CJ, Gajewski B, Siu-kuen AH, Richter K, Cately D, Ellerbeck EF. Change in selfefficacy, autonomous, and controlled motivation predicting smoking. J. Health Psychol. 2012; 17:640-652. [PubMed: 22076554]

DiClemente CC. Motivation for change: implications for substance abuse treatment. Psychol. Sci. 1999; 10:209-213.

Doran N, Spring B, Borrelli B, McChargue D, Hitsman B, Niaura R, Hedeker D. Elevated positive mood: a mixed blessing for abstinence. Psychol. Addict. Behav. 2006; 20:36-43. [PubMed: 16536663]

Fiore, MC.; Bailey, WC.; Cohen, SJ.; Dorfman, SF.; Goldstein, MG.; Gritz, ER.; Heyman, RB.; Jaen, CR.; Kottke, TE.; Lando, HA.; Mecklenburg, RE.; Mullen, PD.; Nett, LM.; Robinson, L.; Stitzer, ML.; Tommasello, AC.; Villejo, L.; Wewers, ME. Treating Tobacco Use and Dependence. Clinical Practice Guideline U.S. Department of Health and Human Services. Rockville, MD: Public Health Service; 2000.

Garvey AJ, Bliss RE, Hitchcock JL, Heinold JW, Rosner B. Predictors of smoking relapse among selfquitters: a report from the Normative Aging Study. Addict. Behav. 1992; 17:367-377. [PubMed: 1502970]

Geschwind N, Peeters F, Drukker M, van Os J, Wichers MJ. Mindfulness training increases momentary positive emotions and reward experience in adults vulnerable to depression: a randomized controlled trial. J. Consult. Clin. Psychol. 2011; 79:618-628. [PubMed: 21767001]

Gwaltney CJ, Metrik J, Kahler CW, Shiffman S. Self-efficacy and smoking cessation: a meta-analysis. Psychol. Addict. Behav. 2009; 23:56-66. [PubMed: 19290690]

Gwaltney CJ, Shiffman S, Sayette MA. Situational correlates of abstinence self-efficacy. J. Abnorm. Psychol. 2005; 114:649-660. [PubMed: 16351386]

Haukkala A, Uutela A, Vartiainen E, McAlister A, Knekt P. Depression and smoking cessation: the role of motivation and self-efficacy. Addict. Behav. 2000; 25:311-316. [PubMed: 10795958]

Heckman CJ, Egleston BL, Hoffman MT. Efficacy of motivational interviewing for smoking cessation: a systematic review and meta-analysis. Tob. Control. 2010; 19:410-416. [PubMed: 20675688]

Heppner WL, Ji L, Reitzel LR, Castro Y, Correa-Fernandez V, Vidrine JI, Li Y, Dolan-Mullen P, Velasquez MM, Cinciripini PM, Cofta-Woerpel L, Greisinger A, Wetter DW. The role of prepartum motivation in the maintenance of postpartum smoking abstinence. Health Psychol. 2011; 30:736-745. [PubMed: 21859215]

Hettema JE, Hendricks PS. Motivational Interviewing for smoking cessation: a meta-analytic review. J. Consult. Clin. Psychol. 2010; 78:868-884. [PubMed: 21114344]

Hughes JR, Keely J, Naud S. Shape of the relapse curve and long-term abstinence among untreated smokers. Addiction. 2004; 99:29-38. [PubMed: 14678060]

Javitz HS, Lerman C, Swan GE. Comparative dynamics of four smoking withdrawal symptom scales. Addiction. 2012; 107:1501-1511. [PubMed: 22321019]

John U, Meyer C, Rumpf HJ, Hapke U. Self-efficacy to refrain from smoking predicted by major depression and nicotine dependence. Addict. Behav. 2004; 29:857-866. [PubMed: 15219330]

Joseph S, Manafi E, Iakovaki AM, Cooper R. Personality, smoking motivation, and self-efficacy to quit. Pers. Individ. Dif. 2003; 34:749-758.

Killen JD, Fortmann SP. Craving is associated with smoking relapse: findings from three prospective studies. Exp. Clin. Psychopharmacol. 1997; 5:137-142. [PubMed: 9234050]

Kim H-Y. Statistical notes for clinical researchers: assessing normal distribution using skewness and kurtosis. Restor. Dent. Endod. 2012; 37:245-248. [PubMed: 23431506]

Linehan, MM. Skills Training Manual for Treating Borderline Personality Disorder. New York: The Guilford Press; 1993.

MacPherson L, Tull MT, Matsiewicx AK, Rodman S, Strong DR, Kahler CW, Hopko DR, Zvolensky MJ, Brown RA, Lejuez CW. Randomized controlled trial of behavioral activation smoking cessation treatment for smokers with elevated depressive symptoms. J. Consult. Clin. Psycol. 2010; 78:56-61. 
Martin RA, Rohsenow DJ, MacKinnon SV, Abrams DB, Monti PM. Correlates of motivation to quit smoking among alcohol dependent patients in residential treatment. Drug Alcohol Depend. 2006; 83:73-78. [PubMed: 16314049]

Martinez E, Tatum KL, Glass M, Bernath A, Ferris D, Reynolds P, Schnoll RA. Correlates of smoking cessation self-efficacy in a community sample of smokers. Addict. Behav. 2010; 35:175-178. [PubMed: 19804945]

Miller, WR.; Rollnick, S. Motivational Interviewing: Preparing People for Change. 2nd ed.. New York: Guilford Press; 2002.

Muthén, LK.; Muthén, BO. Mplus Users Guide. Los Angeles: Muthén and Muthén; 2009.

Niaura R. Cognitive social learning and related perspectives on drug craving. Addiction. 2000; 95:S155-S163. [PubMed: 11002910]

Piasecki TM. Relapse to smoking. Clin. Psychol. Rev. 2006; 26:196-215. [PubMed: 16352382]

Piper ME, Schlam TR, Cook JW, Sheffer MA, Smith SS, Loh WY, Bolt DM, Kim SY, Kaye JT, Hefner KR, Baker TB. Tobacco withdrawal components and their relations with cessation success. Psychopharmacol. 2011; 216:569-578.

Robinson JD, Lam CY, Carter BL, Minnix JA, Cui Y, Versace F, Wetter DW, Cinciripini PM. A multimodal approach to assessing the impact of nicotine dependence, nicotine abstinence, and craving on negative affect in smokers. Exp. Clin. Psychopharmacol. 2011; 19:40-52. [PubMed: 21341922]

Schmukle SC, Egloff B, Burns LR. The relationship between positive and negative affect in the Positive And Negative Affect Schedule. J. Res. Pers. 2002; 36:463-475.

Sheldon KM, Lyumbomirsky S. How to increase and sustain positive emotion: the effects of expressing gratitude and visualizing best possible selves. J. Posit. Psychol. 2006; 1:73-82.

Shiffman S, Dunbar M, Kirchner T, Li X, Tindle H, Anderson S, Scholl S. Smoker reactivity to cues: effects on craving and on smoking cessation. J. Abnorm. Psychol. 2012; 122:264-280. [PubMed: 22708884]

Shiyko MP, Lanza ST, Tan X, Li R, Shiffman S. Using the time-varying effect model (TVEM) to examine dynamic associations between negative affect and self-confidence on smoking urges: differences between successful quitters and relapsers. Prev. Sci. 2012; 13:288-299. [PubMed: 22246429]

Shmueli D, Prochaska JJ. A test of positive affect induction for countering self-control depletion in cigarette smokers. Psychol. Addict. Behav. 2012; 26:157-161. [PubMed: 21553949]

Tiffany ST. A cognitive model of drug urges and drug-use behavior: role of automatic and nonautomatic processes. Psychol. Rev. 1990; 97:147-168. [PubMed: 2186423]

Watson D, Clark LA, Tellegen A. Development and validation of brief measures of positive and negative affect: the PANAS scales. J. Pers. Soc. Psychol. 1988; 54:1063-1070. [PubMed: 3397865]

Welsh SK, Smith SS, Wetter DW, Jorenby DE, Fiore MC, Baker TB. Development and validation of the Wisconsin Smoking Withdrawal Scale. Exp. Clin. Psychopharmacol. 1999; 7:354-361. [PubMed: 10609970]

Wetter DW, Brandon TH, Baker TB. The relation of affective processing measures and smoking motivation indices among college-age smokers. Adv. Behav. Res. Ther. 1992; 14:169-163.

Witkiewitz K, Marlatt GA. Relapse prevention for alcohol and drug problems: that was Zen, this is Tao. Am. Psychol. 2004; 59:224-235. [PubMed: 15149263]

Wray JM, Gass JC, Tiffany ST. A systematic review of the relationships between craving and smoking cessation. Nicotine Tob. Res. 2013; 15:1167-1182. [PubMed: 23291636]

Zinser MC, Baker TB, Sherman JE, Cannon DS. Relation between self-reported affect and drug urges and cravings in continuing and withdrawing smokers. J. Abnorm. Psychol. 1992; 101:617-629. [PubMed: 1430600] 


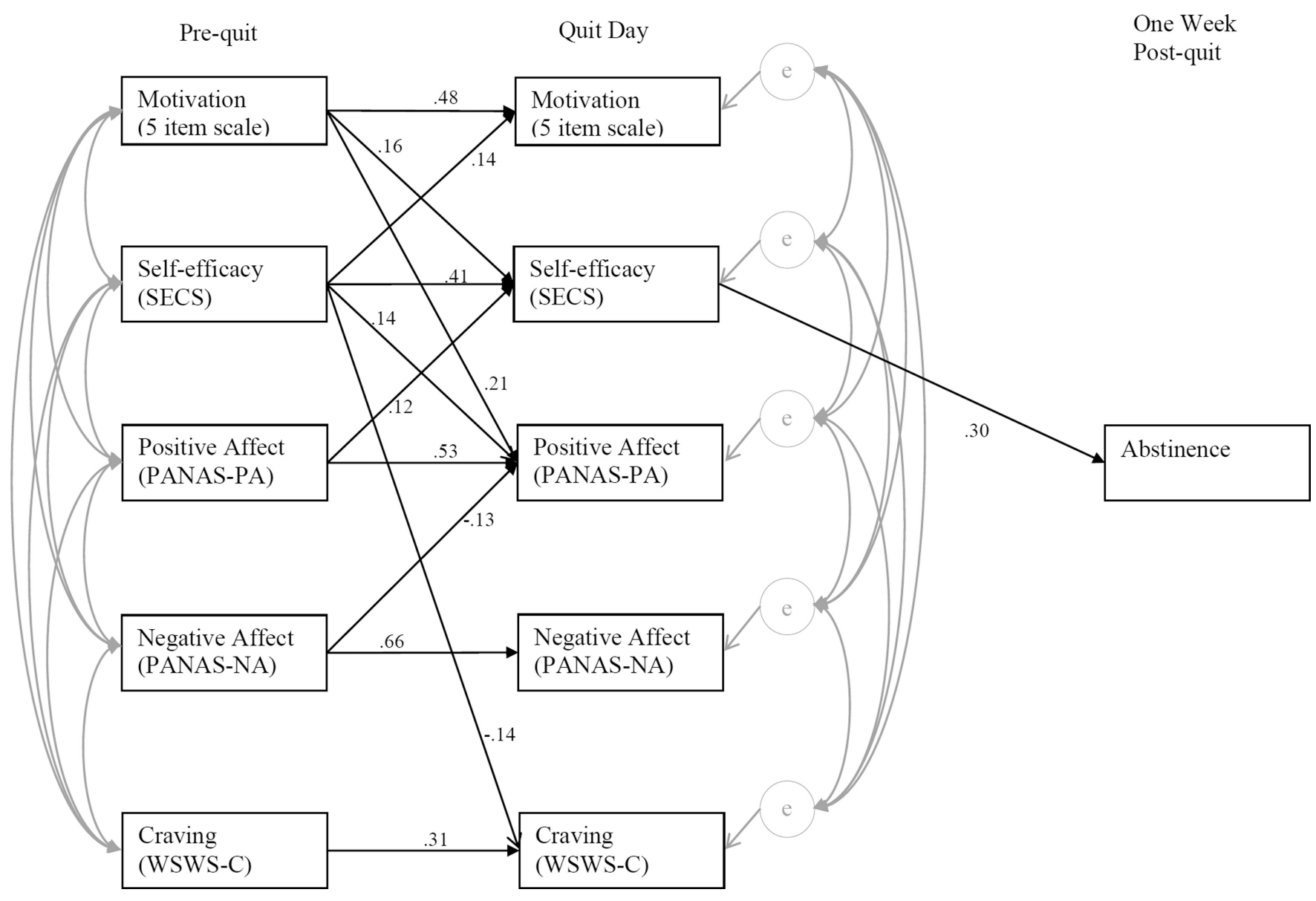

Figure 1.

The Final Model. Note: AIPQ-NS = Affective Information Processing QuestionnaireControl of Affect by Means Other Than Smoking subscale; PANAS-NA= Positive And Negative Affect Schedule-Negative Affect subscale; PANAS-PA=Positive And Negative Affect Schedule-Positive Affect subscale; WSWS-C=Wisconsin Smoking Withdrawal Scale-Craving subscale. Standardized estimates are shown. Model covariances and residual terms are not shown. All paths significant at $p<.01$. 
Table 1

Participant Characteristics

\begin{tabular}{|c|c|c|c|}
\hline & Whites (N=139) & $\begin{array}{l}\text { African Americans } \\
(\mathbf{N}=144)\end{array}$ & Latinos $(N=141)$ \\
\hline \multicolumn{4}{|c|}{ Demographics and Tobacco Use } \\
\hline & \multicolumn{3}{|c|}{ Mean (SD) } \\
\hline \multicolumn{4}{|l|}{1 week abstinence rate } \\
\hline Abstinent & $42(30.2)$ & $37(25.7)$ & $30(21.3)$ \\
\hline Not abstinent & $97(69.8)$ & $107(74.3)$ & $111(78.7)$ \\
\hline Age & $42.82(11.62)$ & $44.76(9.87)$ & $36.02(10.19)^{a b}$ \\
\hline Education & $13.34(2.23)$ & $12.84(1.59)^{a}$ & $12.53(2.06)^{a}$ \\
\hline \multirow[t]{2}{*}{ Cigarettes per day } & $23.47(9.27)$ & $20.94(11.96)$ & $18.96(8.94)^{a b}$ \\
\hline & \multicolumn{3}{|c|}{$\mathrm{N}(\%)$} \\
\hline \multicolumn{4}{|l|}{ Employment status } \\
\hline Not Employed & $64(46.7)$ & $74(52.1)$ & $37(26.6)^{a b}$ \\
\hline Employed & $73(53.3)$ & $68(47.9)$ & $102(73.4)$ \\
\hline \multicolumn{4}{|l|}{ Gender } \\
\hline Male & $61(43.9)$ & $58(40.3)$ & $79(56)^{a b}$ \\
\hline Female & $78(56.1)$ & $86(59.7)$ & $62(44)$ \\
\hline \multicolumn{4}{|l|}{ Income } \\
\hline$\geq \$ 20,000$ & $47(38.5)$ & $76(57.1)^{a}$ & $35(29.2)^{b}$ \\
\hline$<\$ 20,000$ & $75(61.5)$ & $57(42.9)$ & $85(70.8)$ \\
\hline \multicolumn{4}{|l|}{ Partner Status } \\
\hline Has partner & $43(31.2)$ & $35(24.5)$ & $68(48.9)^{a b}$ \\
\hline No partner & $90(68.8)$ & $108(75.5)$ & $71(51.1)$ \\
\hline \multicolumn{4}{|l|}{ Time to $1^{\text {st }}$ cigarette } \\
\hline Within 5 minutes & $77(55.4)$ & $81(56.3)$ & $51(36.2)^{a b}$ \\
\hline 6 minutes or more & $62(44.6)$ & $63(43.8)$ & $90(63.8)$ \\
\hline \multicolumn{4}{|c|}{ Pre-quit Measures } \\
\hline & \multicolumn{3}{|c|}{ Mean (SD) } \\
\hline Motivation & $4.37(.63)$ & $4.43(.67)$ & $4.34(.66)$ \\
\hline PANAS-NA & $19.27(8.06)$ & $19.98(8.52)$ & $20.19(8.27)$ \\
\hline PANAS-PA & $33.14(9.39)$ & $32.45(9.71)$ & $31.18(9.34)$ \\
\hline SECS & $2.71(.74)$ & $2.80(.90)$ & $2.76(.76)$ \\
\hline WSWS-C & $2.58(.80)$ & $2.47(.85)$ & $2.49(.70)$ \\
\hline \multicolumn{4}{|c|}{ Quit-day Measures } \\
\hline & \multicolumn{3}{|c|}{$\mathrm{M}(\mathrm{SD})$} \\
\hline Motivation & $4.58(.58)$ & $4.55(.60)$ & $4.45(.74)$ \\
\hline PANAS-NA & $20.03(8.9)$ & $19.15(7.96)$ & $19.52(7.41)$ \\
\hline
\end{tabular}

Drug Alcohol Depend. Author manuscript; available in PMC 2015 April 01. 


\begin{tabular}{lccc}
\hline & Whites $(\mathbf{N}=\mathbf{1 3 9})$ & $\begin{array}{c}\text { African Americans } \\
(\mathbf{N}=\mathbf{1 4 4})\end{array}$ & Latinos $(\mathbf{N}=\mathbf{1 4 1})$ \\
\hline PANAS-PA & $34.40(9.69)$ & $34.78(8.96)$ & $31.94(9.17)^{a b}$ \\
SECS & $3.3(.88)$ & $3.31(.87)$ & $3.04(.80)^{a b}$ \\
WSWS-C & $2.29(1.02)$ & $2.04(.89)^{a}$ & $2.19(.87)$ \\
\hline
\end{tabular}

Note: PANAS-NA = Positive And Negative Affect Schedule—Negative Affect subscale; PANAS-PA = Positive And Negative Affect SchedulePositive Affect subscale; SECS = Self-efficacy/Confidence Scale; WSWS-C = Wisconsin Smoking Withdrawal Scale—Craving subscale. Four participants did not report education, 6 did not report employment status, 49 did not report income, 4 did not report partner status.

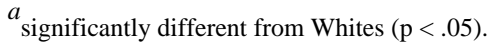

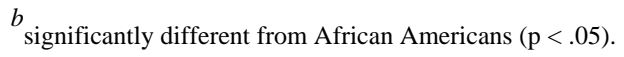




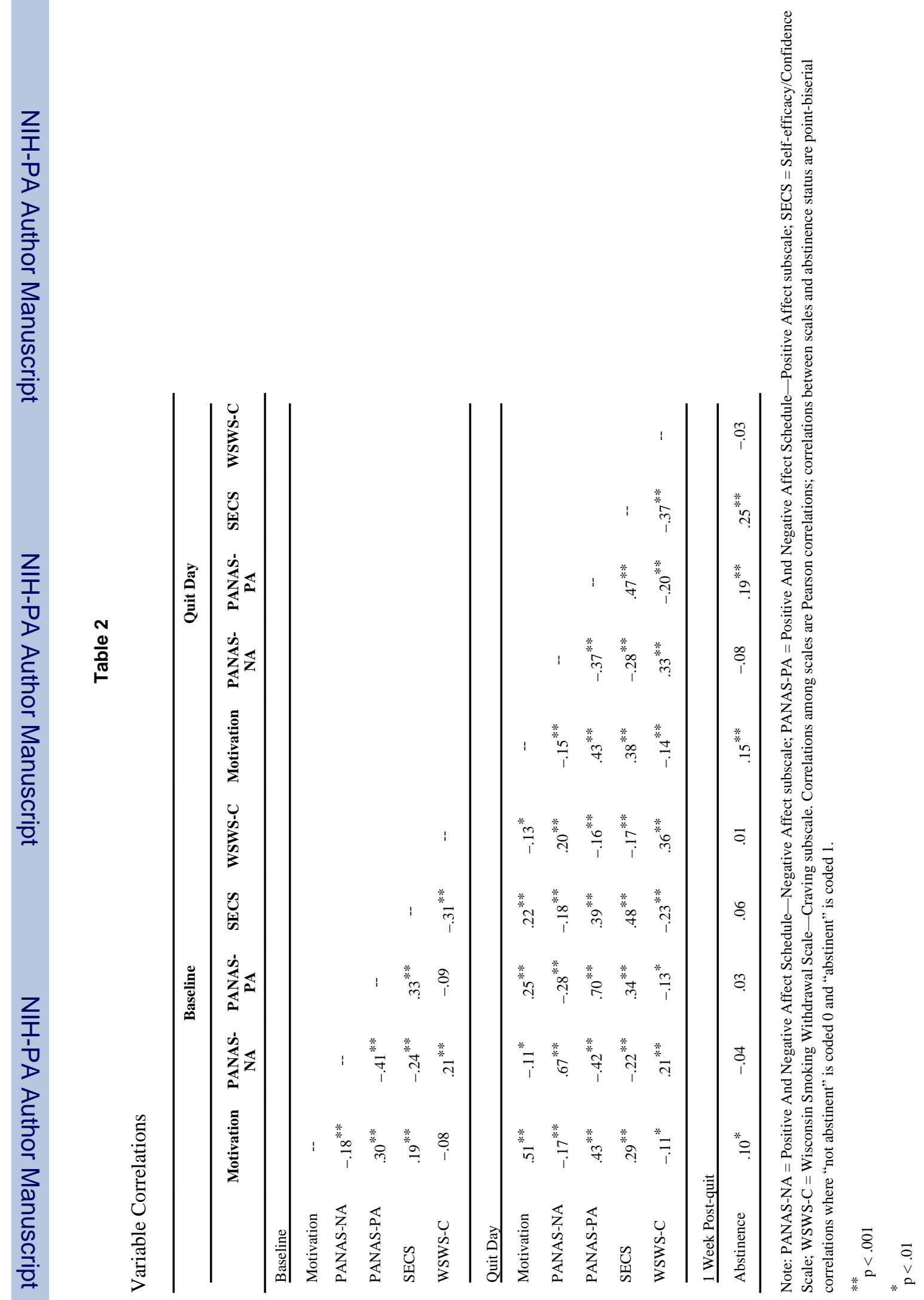

